\title{
Correction: Ly49E Expression on CD8aa- Expressing Intestinal Intraepithelial Lymphocytes Plays No Detectable Role in the Development and Progression of Experimentally Induced Inflammatory Bowel Diseases
}

\author{
The PLOS ONE Staff
}

Dr. Els Louagie is not included in the author byline. She should be listed as the seventh author and affiliated with Department of Rheumatology, Ghent University, Ghent, Belgium. The contributions of this author are as follows: Performed the experiments, analyzed the data, and contributed reagents/materials/analysis tools.

The Funding section should read: This work was supported by grants from the Foundation against Cancer, a foundation of public interest (2010-166) (http://www.kanker.be/grants) (G.L.), by the Fund for Scientific Research (FWO) (G.0187.13) (http://www.fwo.be/en/ fellowships-funding/research-projects/research-project/) (G.L.) and by the BOF of Ghent University (BOF11/GOA/005) (http://www.ugent.be/nl/onderzoek/financiering/bof/goa/overzicht. htm) (J.P, G.L., B.V, T.T.). A.V.A, J.F., M.V. are supported by the Institute for the Promotion of Innovation through Science and Technology Flanders (IWT-Vlaanderen) (http://www.iwt. be/subsidies/sb). S.T. is supported by the BOF of Ghent University. T.K. is supported by the FWO. E.L. is supported by the Interuniversity Attraction Poles Programme of the Belgian Science Policy Office (IAP project DevRepair). The funders had no role in study design, data collection and analysis, decision to publish, or preparation of the manuscript.

\section{Reference}

1. Van Acker A, Filtjens J, Van Welden S, Taveirne S, Van Ammel E, Vanhees M, et al. (2014) Ly49E Expression on CD8aa-Expressing Intestinal Intraepithelial Lymphocytes Plays No Detectable Role in the Development and Progression of Experimentally Induced Inflammatory Bowel Diseases. PLoS ONE 9(10): e110015. doi: 10.1371/journal.pone.0110015 PMID: 25310588

Ly49E Expression on CD8aa-Expressing Intestinal

Intraepithelial Lymphocytes Plays No Detectable Role

in the Development and Progression of

Experimentally Induced Inflammatory Bowel

Diseases. PLoS ONE 10(4): e0124464. doi:10.1371/

journal.pone.0124464

Published: April 9, 2015

Copyright: $\odot 2015$ The PLOS ONE Staff. This is an open access article distributed under the terms of the Creative Commons Attribution License, which permits unrestricted use, distribution, and reproduction in any medium, provided the original author and source are credited. 